\title{
Experimental Study on the Strength of Concrete Drainage Regeneration Xinhua ZHANG ${ }^{1, a}$, Yuxuan ZHAO ${ }^{2, b}$, Huimin TANG $^{2, b}$, Meiou XUE ${ }^{2, b}$, Caixu $\mathrm{ZHOU}{ }^{2, \mathrm{~b}}$
}

\author{
${ }^{1}$ College of Civil Engineering, Shanghai Normal University, Shanghai, 201418, China \\ ${ }^{2}$ College of Civil Engineering, Shanghai Normal University, Shanghai, 201418, China \\ aemail: zhxh152@shnu.edu.cn, bemail: 13162557029@126.com
}

\begin{abstract}
Keywords: Recycled coarse aggregate; Drainage concrete; Compressive strength; Experimental Analysis
\end{abstract}

\begin{abstract}
Since the source of the waste after the concrete complex, the waste concrete made from recycled coarse aggregate processing and many use restrictions, the recycled concrete technology and water treatment technology integration into a concrete drainage concrete, through experimental analysis of the recycled coarse aggregate Water Treatment variation different dosage strength of concrete, considering the strength of recycled concrete and drainage performance requirements, under certain target porosity can be determined in line with the strength requirements of concrete, increase its value in the actual project.
\end{abstract}

\section{Introduction}

With the rapid development of urban redevelopment renovation and expansion, bringing the number of garbage building surge, of which $30 \%$ to $40 \%$ of waste in landfills and only concrete piling, farmland pollute the environment. How to use the waste concrete, for the purpose of protecting natural resources and ecological environment, the world and utilization of waste concrete is always constantly, many countries apply technology matures. China's slow gait of recycled concrete, load-bearing structures such as the current housing construction, bridge construction has not dared to use, only a small amount of recycled concrete for non-vital parts of the road base and so on. Further urban road development process, rainy pavement need to quickly remove water, prevent night reflective water surface, improving road comfort and safety, but also to absorb noise with the vehicle, creating a quiet and comfortable traffic environment. Drainage concrete for road surface defects of the original city, in addition to the sewer drain, but can also allow rainwater flow into the ground, effectively complement the new technology groundwater seepage ventilation drainage concrete in its " Caramel treats" as the cross-sectional structure, water vapor permeation through the pores, but the high compactness of traditional concrete, blocking the water and gas exchange. The waste concrete surface made of recycled coarse aggregate cement mortar porosity greater attachment portion, causing its water absorption was significantly higher than that of natural aggregate, this is just the city roads, green belts, and other ecological garden where it is needed. The combination of these two techniques, the use of appropriate technology gelling bonding with concrete particles saturated bond between the particles there are significant seepage channel. Cementitious materials such as used properly, the appropriate proportion of recycled coarse aggregate, concrete mix appropriate, supplemented by mineral admixtures and superplasticizer joint action, their strength accessible to ordinary concrete and promotion.

\section{Analysis of the Performance of Recycled Concrete}

Waste concrete complex sources, performance discrete, various impurities range, for this group of selected waste recycled coarse aggregate concrete yard of a detection unit of the old concrete. After test analysis: Compared with natural coarse aggregate, recycled coarse aggregate to reduce the apparent density of about $3.9 \%$ to $12.1 \%$, the bulk density is reduced by about $8.2 \%$ to $14.6 \%$; water absorption of recycled coarse aggregate is natural aggregate $3 \sim 13$ times, recycled coarse 
aggregate crushing value is 1.8 to 3.7 times that of natural aggregate. And native higher concrete strength, the greater the recycled coarse aggregate particle breakage resulting higher recycled coarse aggregate apparent density and bulk density, crushing index, water absorption smaller.

Because multiphase ordinary concrete, non-porous and homogeneous and there is a lot of interfacial transition zone, while cement and aggregate interface weakest, the production of recycled coarse aggregate with mechanical crushing method at the interface is easy to produce internal micro fractures or initial injury, adhesion mortar interior also easy to produce internal micro-cracks or initial damage, cracks in the region of ion transport and liquid penetration fast track, directly affect the mechanical properties and durability of concrete. Meanwhile recycled coarse aggregate surface attached to a lot of dust from the cement during grinding friction, such activity minor dust, recycled coarse aggregate and cause the interface between the new cement thicker and weaker.

Regeneration of coarse aggregate in different dosage on compressive strength of recycled concrete lot, but regeneration mechanical properties of concrete test data discrete larger phenomenon appears rough test: Within recycled coarse aggregate content with $30 \%$ gradually increase the strength of concrete is not strong regularity changes; gradual increase with recycled coarse aggregate content within $30 \%$ to $60 \%$ range, concrete strength gradually reduced to $25 \%$ or even more; further increases with recycled coarse aggregate content to over $60 \%$, recycled concrete strength greater scope to reduce.

\section{Water Treatment Concrete Technical Requirements}

Drainage concrete is a porous material composed of coarse aggregate concrete, cementitious materials and water mixing in. No mature mix design method, Pastes coarse aggregate particles bonded to each other drainage concrete, to form a certain strength as a whole. It has good porosity large drainage performance, but the intensity is not high characteristics. This paper consider adding auxiliary materials, to ensure the performance of the premise to meet their water treatment, water treatment in order to obtain certain strength concrete mix.

Because less water treatment concrete grout, trace or no fine aggregate, if at the time of forming the mechanical vibration mode, the grout will gather in the end portion, so that the bottom of the concrete closed lose water treatment capacity. Artificial tamping method, with the increase in the number of tamping, strength and bulk density increases, the gap is reduced, drainage concrete becomes dense, is not conducive to water treatment.

Like ordinary concrete, drainage concrete strength under equal conditions with increasing cement strength increases. Because of its aggregate concrete drainage spacing increased, decreased between the particles occlusal factors, mainly on the strength of the formation strength cement material. Strength concrete drainage and drainage performance by the size of the effect of water-cement ratio, the greater the excess water-cement ratio is easy to produce a slurry, the slurry flows down by gravity, filling the bottom of the hole, affects the drainage effect; water-cement ratio is too low cement strength to play poor, low strength concrete drainage. Stir in full on the basis of a uniform slurry of cementitious material wrapped in coarse aggregate surface, there is no excess slurry flowing, no bottom slurry precipitated.

Fly ash, slag, silica fume and other auxiliary cementing material as mineral admixtures, they are part of an action instead of cement hydration coagulation, increasing the strength of the concrete beneficial; the other role is to significantly improve the rheological properties of concrete Since concrete is no sand filtration components, adding mineral admixture can improve the adhesion of the cement slurry of cementitious material, favorable strength to improve.

Super plasticizer or superplasticizer is an anionic polymer surfactant products are naphthalene sulfonate formaldehyde condensates and melamine sulfonate formaldehyde condensates. Single superplasticizer cement slurry has a strong dispersion, but does not last long, slump loss over time, need super plasticizer and retarder (or retarding superplasticizer) composition used can be extended the flow properties of fresh concrete, to meet concrete mixing, transportation, pumping, pouring, etc. process requirements. 


\section{Test Analysis}

Cement: Conch brand P.O 42.528 day found strength 46.3MPa;

Sand: Sand, fineness modulus of 2.5;

Admixture: Naphthalene superplasticizer, dosage 1.0\%;

Natural coarse aggregate: crushed stone, 5-40mm continuous;

Grain size of mineral admixtures: Silica fume,

Recycled coarse aggregate: Recycled coarse aggregate from the waste concrete crushing, cleaning, and clearing debris, so as to satisfy the cumulative percentage of $5-40 \mathrm{~mm}$ particle size distribution of the test material as recycled coarse aggregate reserve.

The test detects the basic performance of recycled coarse aggregate as in Table 1 below:

Table 1 concrete mix design $\left(\mathrm{kg} / \mathrm{m}^{3}\right)$

\begin{tabular}{|c|c|c|c|c|c|}
\hline Number & $\begin{array}{c}\text { Natural coarse } \\
\text { aggregate }\end{array}$ & $\mathrm{RC}-10$ & $\mathrm{RC}-30$ & $\mathrm{RC}-50$ & $\mathrm{RC}-70$ \\
\hline Cement & 300 & 300 & 300 & 300 & 300 \\
\hline $\begin{array}{c}\text { Replacement rate } \\
(\%)\end{array}$ & 0 & 10 & 30 & 50 & 70 \\
\hline Mineral admixture & 198 & 198 & 198 & 198 & 198 \\
\hline $\begin{array}{c}\text { Native coarse } \\
\text { aggregate }\end{array}$ & 1442 & 1218 & 969 & 721 & 473 \\
\hline $\begin{array}{c}\text { Recycled coarse } \\
\text { aggregate }\end{array}$ & 0 & 134 & 383 & 631 & 879 \\
\hline Water & 135 & 139 & 147 & 155 & 163 \\
\hline Superplasticizer & 3 & 3 & 3 & 3 & 3 \\
\hline
\end{tabular}

Porous recycled coarse aggregate direct mixing recycled concrete will absorb the mixing water, concrete mix design strength of C25, Table 1 Mix by mixing the concrete mixture, the standard curing 28 days and 56 days, were tested for anti- compressive strength (Table 2).

Table 2 concrete strength (MPa)

\begin{tabular}{|c|c|c|c|c|}
\hline Number & fcu-28 & $\begin{array}{c}\text { Rebound in } \\
\text { terms of strength }\end{array}$ & fcu-56 & $\begin{array}{c}\text { Rebound in } \\
\text { terms of strength }\end{array}$ \\
\hline $\begin{array}{c}\text { Natural coarse } \\
\text { aggregate }\end{array}$ & 29.1 & 26.9 & 34.5 & 28.2 \\
\hline RC-10 & 28.8 & 25.4 & 33.4 & 27.6 \\
\hline RC-30 & 27.7 & 26.5 & 32.2 & 27.1 \\
\hline RC-50 & 26.1 & 23.3 & 30.1 & 24.5 \\
\hline RC-70 & 25.3 & 21.1 & 28.4 & 22.2 \\
\hline
\end{tabular}

As can be seen from Table 2, the recycled coarse aggregate replacement rate impact of recycled concrete compressive strength is large, the compressive strength of recycled concrete recycled coarse aggregate increases and decreases. When recycled coarse aggregate replacement rate of 30\% and $70 \%$, recycled concrete $28 \mathrm{~d}$, when the $56 \mathrm{~d}$, respectively, compared with ordinary concrete compressive strength is low. Different age of recycled concrete compressive strength with recycled coarse aggregate content less than $30 \%$ has little effect, but when the content exceeds $30 \%$, with the improvement of content, the concrete strength gradually decline. Drainage concrete skeleton structure model and failure is characterized by the formation of coarse aggregate, cement layer formed Pastes and pore interface between them. Reduced strength for the following reasons: Crushing indicators have shown lower recycled coarse aggregate strength, due to the presence of a large number of micro-cracks within the particles when the nature of injuries the broken concrete, 
cementitious materials and adding new recycled coarse aggregate interface weaker.

\section{Conclusion}

After testing research and analysis, in effect, the need to improve the drainage concrete, recycled concrete quality also need to start solving its stability.

Through recycled coarse aggregate to strengthen and pretreatment, improve recycled coarse aggregate particle shape, removing its surface attachment cement mortar, recycled coarse aggregate to reduce the porosity and secondary crushing and screening processing means to improve the regeneration performance concrete.

Construction technology package using a slurry of coarse aggregate, cementitious material to achieve admixture firmly bonded surface coarse aggregate in the construction process using paving rolling process, reducing the slurry to sink, creating an opening through filtration pores. Ensure preparation of a filtration coefficient, high strength, excellent durability green drainage concrete.

Mixed with further study of ultrafine minerals and admixtures combined effect of interfacial modifier was added to improve the weak areas was recycled coarse aggregate and cement paste between, improve bond strength cementitious material to ensure drainage strength of recycled concrete, conducive to engineering application.

\section{Acknowledgement}

In this paper, this work was financially supported by Innovative projects of Shanghai University Student (A-9103-15-035018).

\section{References}

[1] Mandal S, Gupta A. Strength and durability of recycled aggregate concrete [A]. IABSE Symposium Melbourne [C], Melbourne, Australia, 2002

[2] ACI Committee 318. Building Code Requirements for Structural Concrete (ACI318-02) and Commentary (ACI318R-02) (American Concrete Institute, Detroit), 2002

[3] Mulian Zheng. Porous concrete for drainage base research [D]. Xi'an: Chang'an University, 2004.

[4] Xiaojian Zhuang. Recycled concrete [M]. Beijing: China Building Industry Press, 2008.

[5] Xiaojian Zhuang, Jiabin Li and so on. The compressive strength of recycled concrete research [J]. Tongji University: Natural Science Edition, 2004,32 (12).

[6] Shuhua Liu, luminescence. Recycled concrete technology [M]. Beijing: China Building Materials Industry Press, 2007.

[7] Haidong Wang, Ming Liaoyao, Zijiang Yang. Recycling waste concrete research [J]. Energy conservation, 2006 (11): 44-46.

[8] Liang Huo. Preparation and properties of pervious concrete pavement materials [D]. Southeast University, 2004.

[9] Jing Yang, Guoliang Jiang. Research permeable concrete pavement material strength [J]. Concrete, 2000 (10): 27-30. 